\title{
An enhanced technology of pear compote production through direct blanching with sugar syrup in glass jars and a device for its implementation
}

\author{
Magomed Akhmetov ${ }^{1, *}$, Amiiat Demirova ${ }^{1}$, Zaurbek Abdulkhalikov ${ }^{1}$, Tatiana Daudova ${ }^{1}$, and Leila Daudova $^{2}$ \\ ${ }^{1}$ FSBEO HE Dagestan State Technical University, Makhachkala, Russia \\ ${ }^{2}$ FSBEO HE Dagestan State Agrarian University named after M.M. Jambulatov, Makhachkala, Russia
}

\begin{abstract}
In this article we review and propose new technical solutions to improve the production technology of pear compote with the use of a new method of advanced preparation of fruits through blanching them with sugar syrup in glass jars and accelerated pasteurization modes. The effectiveness of the use of blanching fruits in sugar syrup directly in jars after packing and before filling with syrup, as opposed to blanching them in various technological liquids, is scientifically substantiated. To implement this method, a device for heating fruits in jars in heat transfer fluid has been developed and used. The use of blanching fruit in sugar syrup in jars and accelerated heat treatment regimes intensifies the thermal processing and, as a result, reduces the duration of pasteurization regimes and improves the product quality from the point of view of biologically active components contents. It was revealed that blanching the fruit in jars with $5 \%$ sugar syrup at a temperature of $95{ }^{\circ} \mathrm{C}$ followed by a syrup with a temperature of $98{ }^{\circ} \mathrm{C}$ provides the initial temperature of the product in a jar of $75-76^{\circ} \mathrm{C}$, while according to traditional technology the temperature of the product before sealing is within $45-48{ }^{\circ} \mathrm{C}$. Based on the experimental studies, new modes of pasteurization of pear compote have been developed, taking into account the increased temperature of the product in the jars before sealing. Comprehensive evaluation of the results of the studies allows us to conclude that the implementation of the proposed technical solutions in the production of pear compote, as ensuring the safety of the finished product and improving its quality, is effective.
\end{abstract}

\section{Introduction}

Improving technology using high-tech processes [1], for the production of foods with high consumer properties [2], is an important area of improving the efficiency of food technology processes. The production of pear compote requires a process of preliminary heat treatment of fruits-blanching [3, 4], which is carried out in the solution of $0.1 \%$ acids (wine stone or lemon) and $5-10 \%$ sugar syrup (for boiling soft varieties) at a temperature of $90-100^{\circ} \mathrm{C}$ without subsequent cooling in water.

The disadvantages of this process is that there are difficulties with depositing blanched fruits with a relatively high temperature in the glass jars immediately after the completion of the blanching process, as they need to be laid off for a certain time to reduce temperature to the level that allows them to be laid manually in jars, and as a result, the temperature level of the product as a whole is reduced before sealing, which does not allow the use of accelerated sterilization regimes.

Pasteurization is a mandatory final step in the production of canned products in sealed containers $[5,6$, $7,8,9]$, the task of which is to suppress the life of microorganisms and ensure industrial sterility for longterm storage of products.

However, in the process of pasteurization, depending on its level of perfection, which is determined by the duration and uniformity of the heat treatment of the product, there are also undesirable processes that impair the quality of the product, caused by excessive thermal effects on biologically active components contained in the raw material.

At the same time, the pasteurization process is also the most energy-intensive process in the production cycle, so finding ways to optimize energy costs while ensuring high quality of the product is the most important task in the technology of production of canned compotes.

The goal of this work is to develop new technical solutions for the implementation of heat transfer processes in the production of pear compote, based on direct blanching of fruits with sugar syrup after laying them in jars and new accelerated modes of thermal sterilization, taking into account the increased temperature of the product in the jars before they are sealed.

\footnotetext{
* Corresponding author: akhmag49@mail.ru
} 


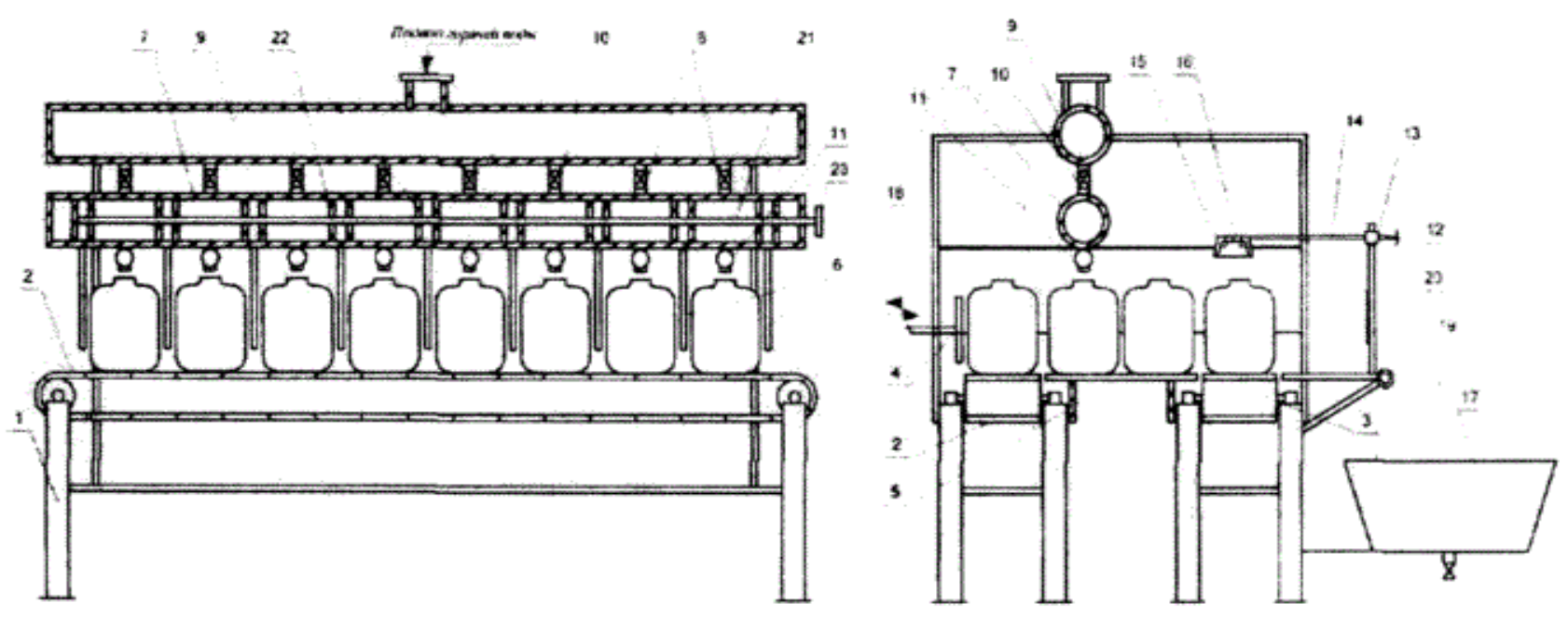

Fig. 1. The device for thermal processing of fruits and vegetables in jars: 1 - frame; 2, 3 - inlet and outlet transporters; 4 - jars pusher; 5 - receiving table for jars; 6 - guides, 7 - volume dispenser; 8 - dispenser sections; 9 - syrup receiver, 10,11 - valves, 12 - racks, 13 - sleeves; 14 - planks, 15 - conical grip; 16 - base of the conical grip; 17 - drained syrup collector; 18 - glass jars filled with product; 19 - hinge; 20 - thrust plate; 21 - rod; 22 - flat pistons;23 - flywheel.

\section{Methods}

The pear compote and thermal processing used in its production are selected as objects of study.

The study of heat transfer processes during pasteurization of pear compote was carried out on an experimental installation.

The temperature of the product was measured by $\mathrm{Cr}$ $\mathrm{Ni}$ and $\mathrm{Cu}-\mathrm{Ni}$ thermocouple made of wire with a diameter of $0.15 \mathrm{~mm}$ and connected to the self-recording potentiometer KSP-4.

\section{Results}

To implement the process of blanching the fruit, we have designed a device [10] (Figure 1) that ensures the implementation of the process of blanching the fruit directly in the glass jars by filling them with 5\% sugar syrup and subsequently replacing it with syrup of the required concentration and temperature of $98{ }^{\circ} \mathrm{C}$ followed by accelerated mode pasteurization.

The diagram of the device is shown in Figure 1. The device works in the following fashion. We preliminarily set the required volume of syrup for pouring into the jars, by moving flat pistons 22. Jars with stacked fruits arrive in the device on the transporter 2 . When the transporter stops, the jars are pushed to the receiving table 5. The next batch of jars coming to the receiving table pushes the jars with the already blanched fruit on the diverting transporter, and in their place gets the next batch of jars. The jars on the outlet transporter are captured and turned, thus removing the syrup, and then they are further transported and allocated to the syrup filler.

In order to evaluate traditional and develop new modes of pasteurization of pear compote, experimental studies on the warming of pear compote according to the traditional technology mode have been conducted.

Charts of temperature and expiration rate changes in pasteurization of pear compote in the CKO 1-82-500 type jar by traditional technology under the mode $\frac{20-30-20}{100} \cdot 218 \mathrm{kPa}$ are shown in Figure 2.

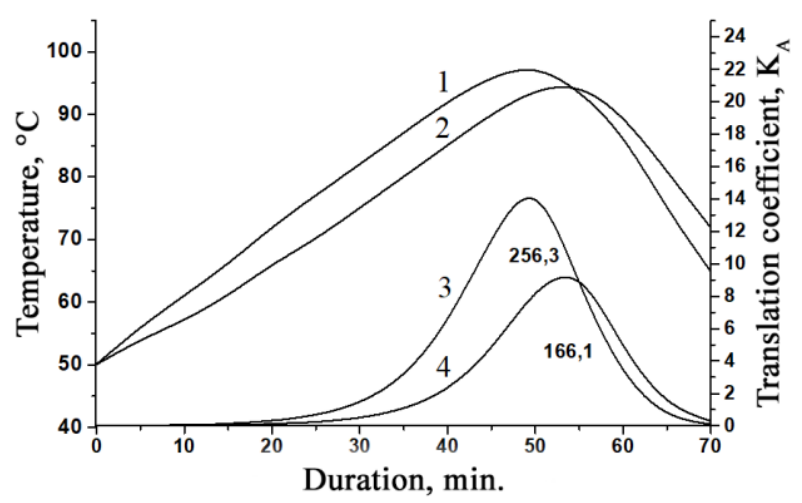

Fig. 2. Charts of temperature changes $(1,2)$ and microflora expiration rate $(3,4)$ during pasteurization of pear compote in the CKO 1-82-500 jar according to the traditional technology.

As can be seen from the graph, the regime is characterized by its long duration of 70 minutes; the product in the jar receives uneven thermal impact, and in the wall area there are multiple excessive heat impacts, as opposed to the central area, which results in a decrease in the quality of the product. We should also note that the initial temperature of the product before pasteurization is $48^{\circ} \mathrm{C}$.

To intensify the pasteurization process, we used a new method of blanching the fruit in the jars with 5\% sugar syrup directly in the jars, and then replacing it with syrup at a temperature of $98{ }^{\circ} \mathrm{C}$, which simultaneously 
ensures the blanching of the fruit and raises the starting temperature of the product to $75^{\circ} \mathrm{C}$,

Charts of changes in temperature and expiration rate of the microflora when pasteurization of pear compote in the CKO 1-82-500 jars using direct blanching of product in the jars with syrup temperature of $90^{\circ} \mathrm{C}$ with pasteurization under the new mode [7] $\frac{10-25-20}{100} \cdot 218 \mathrm{kPa}$, where 10,25 and 20 are, respectively, times of the cycles of heating water in the autoclave from the initial $\left(85^{\circ} \mathrm{C}\right)$ to the final $\left(100{ }^{\circ} \mathrm{C}\right)$ temperatures, pasteurization at $100{ }^{\circ} \mathrm{C}$ and reduction to $40{ }^{\circ} \mathrm{C}$.

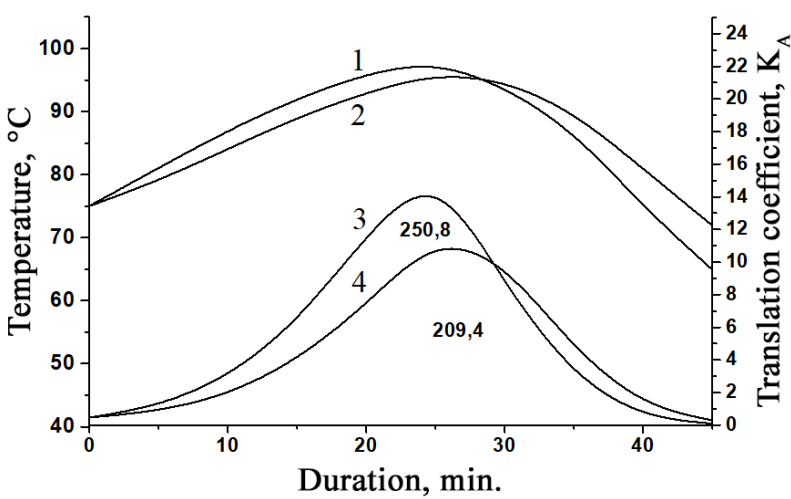

Fig. 3. Charts of temperature changes $(1,2)$ and microflora expiration rate $(3,4)$ during pasteurization of pear compote in the CKO 1-82-500 jar according to the proposed technology.

Evaluation of the results of the pasteurization of the pear compote, depicted graphically in the Figure 3, shows that the developed pasteurization regime achieves the required values of sterilizing effects [11], both in the peripheral and central points of the product, which provides the required industrial sterility of the product. Moreover, the temperature drop between peripheral and central product layers is somewhat less sharp than during traditional pasteurization mode, which means that relatively uniform thermal treatment is provided.

\section{Discussion}

The studies confirm the effectiveness of the developed design of the device for direct blanching of fruits in jars with sugar syrup and accelerated thermal pasteurization regimes.

The research makes it possible to offer an improved technology for the production of pear compote (Figure 4).

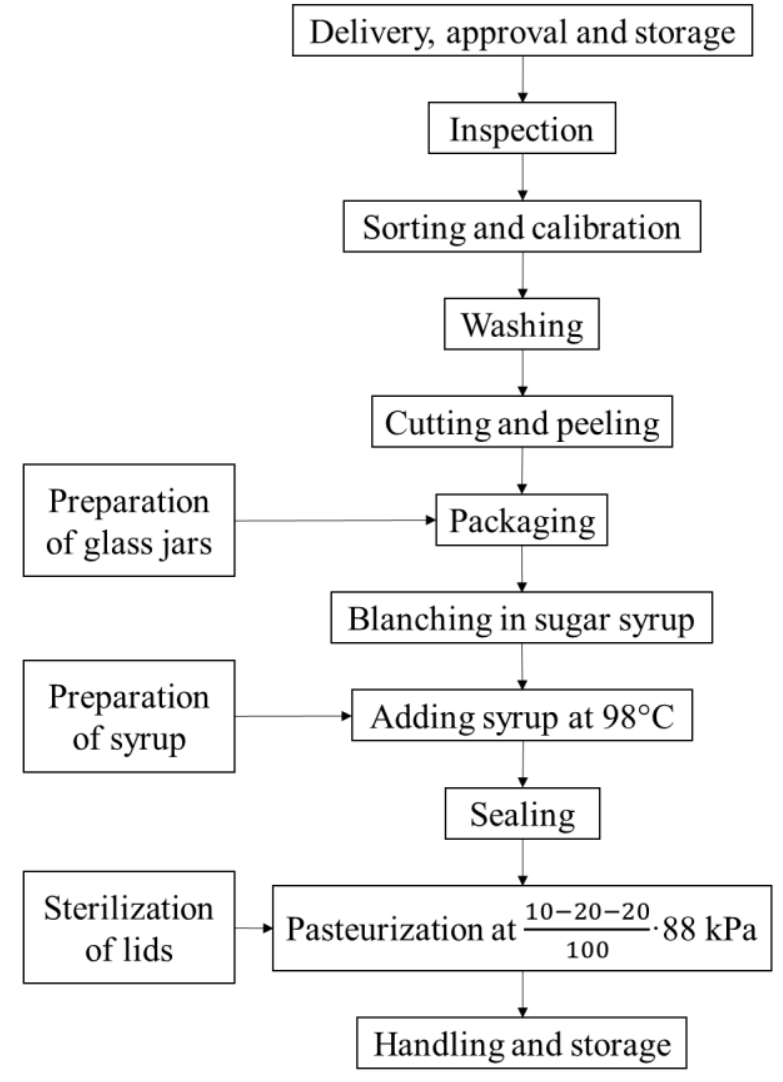

Fig. 4. Advanced technology of pear compote production through direct blanching with sugar syrup in glass jars and accelerated pasteurization mode.

Physical, chemical and microbiological studies have confirmed the high quality and microbiological safety of the product.

The content of vitamin $\mathrm{C}(\mathrm{mg} / 100 \mathrm{~g})$ in pear compote produced by different technologies is presented in Figure 5.

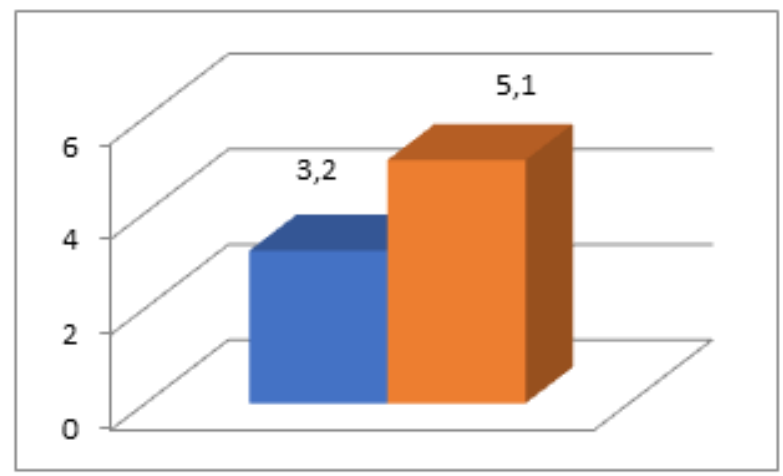

Fig. 5. Vitamin C content $(\mathrm{mg} / 100 \mathrm{~g})$ in pear compote depending on production technology: 1 - traditional technology; 2 -improved technology.

As we can see from the Figure 5, the improved technology ensures the production of high quality products, especially in terms of the content of biologically active components (vitamins), the loss of which when using traditional technology happens due to leaching them during the process of water blanching, as 
well as due to unevenness and long duration of heat treatment.

The results of microbiological studies of pear compote prepared using proposed technology are presented in Table 1.

Table 1. Results of microbiological studies of pear compote produced using the improved technology.

\begin{tabular}{|l|l|c|}
\hline \multicolumn{1}{|c|}{ Indicators } & Results & $\begin{array}{c}\text { Regulatory } \\
\text { documentation of } \\
\text { research }\end{array}$ \\
\hline Molds, CFU/g & Not found & GOST 10444.12-88 \\
\hline Cl.perfringens, in 1.0 g & Not found & GOST 10444.9-88 \\
\hline Yeast, CFU/g & Not found & GOST 10444.12-88 \\
\hline Cl.botulinum, in 1.0 g & Not found & GOST 29185-91 \\
\hline S.aureus, in 1.0 g & Not found & GOST 10444. 2-94 \\
\hline B.cereus, in 1.0 g & Not found & GOST 10444.8-88 \\
\hline $\begin{array}{l}\text { Pathogenic, including } \\
\text { salmonella, in 1.0 g }\end{array}$ & Not found & $\begin{array}{c}\text { GOST 30519-97 } \\
\text { (GOST R 50480-93) }\end{array}$ \\
\hline $\begin{array}{l}\text { Mesophilic aerobic and } \\
\text { optional anaerobic } \\
\text { microorganisms, in 1.0 g }\end{array}$ & Not found & GOST 30425-97 \\
\hline $\begin{array}{l}\text { The number of mesophilic } \\
\text { aerobic and optional } \\
\text { anaerobic } \\
\text { microorganisms, CFU/g }\end{array}$ & Not found & GOST 10444.15 -94 \\
\hline
\end{tabular}

\section{Conclusion}

Studies show that the use of direct blanching with sugar syrup in glass jars increases the temperature of the product compared to traditional technology by $30{ }^{\circ} \mathrm{C}$, allowing the pasteurization process to be carried out in accelerated modes, the duration of which is more than $25 \%$ shorter than that of the modes used during the traditional technology. In addition, thermal energy is saved, since the temperature of the product entering the pasteurization stage is higher.

These technical solutions can be recommended for use in agro-industrial complex enterprises as providing high quality and safety of the product, and resource conservation.

The studies were supported by a grant from the Head of the Republic of Dagestan 2019.

\section{References}

[1] G. Kasyanov, T. Davydenko, High-tech processing of secondary resources of winemaking, Food Science and Technology, 11, 1 (2017).

[2] K. Sakibaev, L. Pylypenko, T. Nikitchina, G. Kasyanov, Improvement of technology and assessment of consumer properties of breakfast cereals, Food Science and Technology, 13, 2 (2019).

[3] Collection of technological instructions for the production of canned goods, vol. 2, Food Industry VNIIKOP, Moscow, 355 (1977).

[4] B.L. Flaumenbaum, S.S. Tanchev, M.A. Grishin, Basics of Food Sterilization, Agropromizdat, Moscow, 264 (1986).
[5] V.P. Babarin, Canned sterilization, GIORD, St. Petersburg, 312 (2006).

[6] M.E. Akhmedov, Intensification of thermal sterilization technology of canned "Compote of apples" with preheating of fruit in the EMF microwave, Bulletin of universities, Food technology, 1, 15-16 (2008).

[7] G.I. Kasyanov, A.F. Demirova, M.E. Akhmedov, Innovative technology of sterilization of fruit and vegetable raw materials, Reports of the Russian Academy of Agricultural Sciences, 6, 57-59 (2014).

[8] G.I. Kasyanov, Prospects for processing food raw materials by low frequency electromagnetic field, Bulletin of universities, Food Technology, 1 (2014).

[9] O.R. Panina, G.I. Kasyanov, S.V. Rohman, Development of microwave-sterilization regimes of lunch cans, Bulletin of universities, Food Technology, 1 (2014).

[10] M.E. Akhmedov, N.G. Zagirov, A.F. Demirova, M.M. Akhmedov, R.A. Rachmanova, Device for heating fruits and vegetables in glass jars, Patent of Russian Federation, 2666371 (07.09.2018).

[11] Guide to developing sterilization and pasteurization modes for canned products, established by GNU VNIIKOP (2011). 